\title{
Effect of IOP based infusion system with and without balanced phaco tip on cumulative dissipated energy and estimated fluid usage in comparison to gravity fed infusion in torsional phacoemulsification
}

\author{
Praveen K. Malik, Taru Dewan ${ }^{*}$ (D), Arun Kr Patidar and Ekta Sain
}

\begin{abstract}
Background: To evaluate the effect of three different combinations of tip designs and infusion systems in torsional phacoemulsification (INFINITI and CENTURION) in patients with cataract. According to the manufacturer, two unique improvements in the Centurion are: active fluid dynamic management system and use of an intrepid balanced tip. The study specifically aimed to evaluate the beneficial effects, if any, of change in tip design and infusion system individually and in combination on both per-operative parameters as well as endothelial health over 6 months.

Methods: One hundred and twenty six consenting patients of grade 4.0-6.9 senile cataract were randomized into three groups for phacoemulsification: Group A ( $n=42)$ : Gravity fed infusion system and $45^{\circ}$ Kelman miniflared ABS phaco tip; Group B ( $n=42)$ : intraocular pressure (IOP) based infusion system and $45^{\circ}$ Kelman miniflared ABS phaco tip; Group C ( $n=42)$ : IOP based infusion system and $45^{\circ}$ Intrepid balanced phaco tip. The cumulative dissipated energy (CDE), estimated fluid usage (EFU) and total aspiration time (TAT) were compared peroperatively. The endothelial parameters were followed up postoperatively for six months.

Results: The three arms were matched for age $(p=0.525)$, gender $(p=0.96)$ and grade of cataract $(p=0.177)$. Group C was associated with significant reductions in CDE $(p=0.001)$, EFU $(p<0.0005)$ as well as TAT $(p=0.001)$ in comparison to the other groups. All three groups had comparable baseline endothelial cell density $(p=0.876)$ and central corneal thickness $(p=0.561)$. On post-operative evaluation, although all groups were comparable till 3 months, by 6 months, the percentage losses in endothelial cell density were significantly lower in group $C$ as compared to the other groups.
\end{abstract}

Conclusions: Use of an IOP based phacoemulsification system in association with use of the Intrepid balanced tip reduces the CDE, EFU and TAT in comparison to a gravity fed system with a mini flared tip or IOP based system with a mini flared tip while also providing better endothelial preservation thus favouring the use of an IOP fed system with a balanced tip.

Trial registration: Trial registration No.: CTRI/2016/06/007022.

Keywords: Active fluidics, CENTURION active, Centurion, IOP based infusion, Torsional, Phacoemulsification, Intrepid balanced tip, Kelman miniflared tip, Gravity based infusion, Cumulative dissipated energy

\footnotetext{
* Correspondence: tarudewan@hotmail.com

Dr Ram Manohar Lohia Hospital, New Delhi, India
} 


\section{Background}

The ultimate aim of every phacoemulsification platform is an energy efficient, time efficient yet safest possible surgical system. While an efficient phacosystem should aim at smooth, fast and well controlled phacoemulsification, minimum complication rates must accompany to complement the same. The intensity and duration of ultrasonic insult have a bearing on endothelial losses, hence the aim is to deliver the lowest energy in the eye and reduce ultrasound time simultaneously [1].

Phacoemulsification platforms have evolved to reduce intracameral ultrasound energy by introducing not only novel energy delivery techniques like micropulse, burst, torsional ultrasound, but also improvising on tip designs to have better hold, cutting efficiency and smooth aspiration [2]. However, some surgeons rank the fluidic control as having paramount importance in achieving breakthrough in phacoemulsification, attaching only secondary importance to tip designs [3].

When Centurion was launched by Alcon, the company claimed dramatic reduction of cumulative dissipated energy (CDE) in comparison to the earlier Infiniti; the claims have been verified by some independent studies [4]. The balanced tip in the Centurion has been shown to lead to lower CDE, however, a major difference also lies in the infusion system of the two platforms [5]. The superior anterior chamber stability of an intraocular pressure (IOP) fed system is hoped not only to make surgery smoother and faster, but also to protect the endothelium. Hence, to attribute all the benefit either to the balanced tip or the IOP fed infusion is not possible unless they are separately compared with identical settings for the rest of the parameters [6]. With this in mind, we designed this three arm comparative study in which first Infiniti and Centurion were compared using the same mini flared tip to find the individual effect of fluidic systems and then the miniflare tip and balanced tip were compared in the Centurion to find the specific advantage offered by this tip design.

Certain intraoperative parameters such as CDE, estimated fluid usage (EFU) and total aspiration time (TAT) can provide a comparison between any two phacoemulsification systems in terms of efficiency, but a study of the endothelium is mandatory to prove the real benefit as we treat the eye as a whole and a reduction of any factor at the cost to the endothelium is pointless. Therefore, we designed this study to compare both CDE as well as endothelial status post-operatively.

\section{Methods}

This prospective randomized control trial was conducted in the Department of Ophthalmology, Post Graduate Institute for Medical Education and Research, Dr. Ram Manohar Lohia Hospital, New Delhi, India. The study was approved by the Institutional Ethics Committee and followed the tenets of Helsinki.

A pilot study found a mean CDE to be $30 \%$-secs with standard deviation (SD) of $\pm 5.5 \%$-secs using gravity fed infusion and $45^{\circ}$ Kelman miniflared ABS phaco tip for phacoemulsification. With a minimum number of 40 patients in each group, the study was expected to have $95 \%$ power to detect a difference of $15 \%$ in each group for phacoemulsification at $95 \%$ significance level using the student's t-test.

Previously diagnosed patients of cataract reporting to the eye out patient department of Dr. RML hospital were approached to participate in the study. After a written informed consent, detailed history pertaining to the patient's background, medical \& ophthalmic complaints were taken. A comprehensive pre-operative eye examination was performed in each patient. Grading of cataract into grades 1.0-6.9 was done according to Lens Opacities Classification System III (LOCS III) classification. The cases with $\mathrm{NO} / \mathrm{NC} 4.0$ to 6.9 were included in the study.

Patients with pre-operative endothelial cell density (ECD) count less than 1500 cells $/ \mathrm{mm}^{2}$, all eye pathologies that can compromise the visual recovery, eyes with any kind of corneal dystrophy or corneal scars preventing visualization of cataract for reliable grading, subluxated or dislocated lens, raised intraocular pressure (> $21 \mathrm{mmHg}$ ) and cases with history of previous intraocular surgery were excluded from the study. A preoperative specular microscopy using Noncontact specular microscope (EM -3000; TOMEY: VERSION 2A/OJ) was done for all cases.

One eye of each patient that fulfilled the inclusion criteria was allocated to the study. Participants were randomly distributed by an independent observer using an envelope technique into three groups: group A undergoing phacoemulsification using gravity fed infusion system and miniflared phaco tip; group B undergoing phacoemulsification using IOP based infusion system and miniflared phaco tip; and group $\mathrm{C}$ undergoing phacoemulsification using IOP based infusion system and balanced phaco tip.

\section{Surgical technique}

The operations were performed by one surgeon (PKM) experienced in the technique within 1 month of recruitment. Uniform pre-regime of dilatation of the pupil was done with tropicamide $(0.8 \%)+$ phenylephrine hydrochloride (5\%) eye drops every 15 mins for 45 mins before surgery. Plain tropicamide was used in hypertensive patients. All surgeries were performed under topical anaesthesia or peribulbar block with $2 \%$ lidocaine + adrenaline $+0.5 \%$ bupivacaine with hyaluronidase Adrenaline was omitted in hypertensive patients. All surgeries were performed through a $2.2 \mathrm{~mm}$ incision. 
Ultrasleeves $(2.2 \mathrm{~mm})$ were used with Infiniti while new generation sleeves were used with the Centurion system. Following capsulorhexis, hydrodissection and rotation, the nucleus was dissembled by direct phaco chop technique. Phacoemulsification was done at $500 \mathrm{mmHg}$ vacuum and aspiration flow rate of $40 \mathrm{~cm}^{3} / \mathrm{min}$ and $1-100 \%$ torsional phacoemulsification with IP setting at $10 \mathrm{~ms}$ and 1:1 ratio in all three groups. The cases were done at a bottle height of $110 \mathrm{~cm}$ in group $\mathrm{A}$ and at an IOP of $55 \mathrm{mmHg}$ in groups B and C followed by irrigation and aspiration and IOL insertion.

\section{Per-operative outcome variables}

At the time of surgery, CDE, EFU and TAT were noted in each group. Any surgical complication was also noted.

\section{Post-operative evaluation}

Post-operative evaluation included specular microscopy at 1 week, 1, 3 and 6 months and visual acuity at 1 month after the surgery by a third observer who was neither the operating surgeon nor was aware of the surgical technique performed on the patient to avoid bias. Noncontact specular microscope (EM - 3000; TOMEY: VERSION 2A/OJ) was used to calculate ECD, coefficient of variance $(\mathrm{CV})$ of cell size, percentage of hexagonal endothelial cells and corneal thickness before surgery and at each postoperative visit. Three endothelial cell photographs were taken at each visit and the mean cell count of three photographs was calculated. Endothelial cell loss was calculated as a percentage of pre-operative cell density. Visual acuity was tested using Snellen's chart; it was converted into the logMAR scale for comparison.

\section{Statistical analysis}

Categorical variables were presented in numbers and percentages (\%) and continuous variables were presented as mean $\pm \mathrm{SD}$ and median. Normality of data was tested using the Kolmogorov-Smirnov test. If the normality was rejected then a non-parametric test was used. Statistical tests were applied as follows:

1. Quantitative variables were compared using ANOVA/Kruskal-Wallis test (when the data sets were not normally distributed) between the three groups and ANCOVA for comparison after adjusting for confounding factors.

2. Qualitative variables were compared using Chi-Square test/Fisher's exact test. A $p$ value of $<0.05$ was considered statistically significant.

The data was entered in MS EXCEL spreadsheet and analysis was done using Statistical Package for Social Sciences (SPSS) version 21.0.

\section{Results}

One hundred and twenty six eyes of 126 patients were randomized into three arms during the study.

Group A $(n=42)$ : Gravity fed infusion system (INFINITY Vision System) and $45^{\circ}$ Kelman miniflared ABS phaco tip (Alcon Laboratories, Inc., Fort Worth, TX, USA).

Group B $(n=42)$ : IOP based infusion system (CENTURION Vision System) and $45^{\circ}$ Kelman miniflared ABS phaco tip (Alcon Laboratories, Inc., Fort Worth, TX, USA).

Group C $(n=42)$ : IOP based infusion system (CENTURION Vision System) and $45^{\circ}$ Intrepid balanced phaco tip. (Alcon Laboratories, Inc., Fort Worth, TX, USA).

The demographics are demonstrated in Table 1. The three arms were matched for Age $(p=0.60)$, Gender $(p=0.96)$, Nuclear Colour $(p=0.17)$ and Nuclear Opalescence $(p=0.121)$. The nuclear grade positively correlated with age of the patient. Coaxial phacoemulsification was done in all cases. There was no incidence of posterior capsular rupture.

Peroperative records of CDE, EFU and TAT were compared. The analysis revealed that a higher grade of nuclear cataract significantly correlated with higher CDE, EFU and TAT (Table 2).

Kruskal Wallis test was applied to compare the peroperative parameters between the three groups and it was found that difference in CDE in group B when compared to group A was not statistically significant but a significantly low $\mathrm{CDE}$ was seen in group $\mathrm{C}$ in comparison to groups $\mathrm{A}$ and $\mathrm{B}(p=0.001)$.

EFU was not significantly lower in group B when compared to group A, however, it was significantly lower in group $\mathrm{C}$ in comparison to group $\mathrm{A}$ as well as group $\mathrm{B}$ $(p<0.0005)$.

TAT was not significantly lower in group B when compared to group A, but was significantly lower in group $C$ when compared to groups A and B ( $p=0.001)$ (Table 3$)$.

Thus, our results demonstrated that it is not just a change in infusion platform but a change in tip design that is associated with significant reductions in CDE, EFU as well as TAT. However, one of the main purposes of achieving such parameters is the intended safety for endothelium. Thus, we analysed the postoperative endothelial parameters as shown in (Table 4).

All three groups had comparable baseline ECD $(p=0.876)$ and central corneal thickness (CCT) $(p=0.561)$ but the CV was significantly lower in group B in comparison to groups $\mathrm{A}$ and $\mathrm{C}(p=0.022)$ and hexagonal endothelial cell count was comparable between groups $\mathrm{A}$ and $\mathrm{B}$ but significantly lower in group C $(p=0.004)$.

Post-operative evaluation at 1 week, 1 month, 3 months and 6 months found that at all visits, ECD was in the 
Table 1 Demographic parameters

\begin{tabular}{lllll}
\hline & Group A & Group B & Group C & $p$ value \\
\hline Age (years) & & & & 0.525 \\
Sample size & 42 & 42 & 42 & \\
Mean \pm Stdev & $62.38 \pm 11.35$ & $64.10 \pm 9.57$ & $64.76 \pm 8.56$ & \\
Median & 60.5 & 62.5 & 64.5 & \\
Min-Max & $42-92$ & $42-87$ & $50-86$ & \\
Inter quartile & $56-68$ & $59-71$ & $59-70$ & \\
range & & & & 0.177 \\
NC (LOCSw) & & & & \\
Sample size & 42 & 42 & 42 & \\
Mean \pm Stdev & $5.34 \pm 0.89$ & $5.52 \pm 0.78$ & $5.2 \pm 0.9$ & \\
Median & 5.2 & 5.5 & 5.2 & \\
Min-Max & $4.0-6.9$ & $4.0-6.9$ & $4.0-6.9$ & \\
Inter quartile & $5.0-6.0$ & $5.0-6.0$ & $4.5-5.5$ & \\
range & & & & \\
NO (LOCSw) & & & & \\
Sample size & 42 & 42 & 42 & \\
Mean \pm Stdev & $4.91 \pm 0.84$ & $5.05 \pm 0.63$ & $4.78 \pm 0.87$ & \\
Median & 4.7 & 5.0 & 4.7 & \\
Min-Max & $3.5-6.5$ & $3.5-6.0$ & $3.5-6.9$ & \\
Inter quartile & $4.5-5.5$ & $4.5-5.5$ & $4.0-5.0$ & \\
range & & & & \\
\hline
\end{tabular}

$N C=$ nuclear colour, $N O=$ nuclear opalescence

order $\mathrm{B}>\mathrm{A}>\mathrm{C}$ and Corneal Thickness was in the order $\mathrm{B}<\mathrm{A}<\mathrm{C}$, but none of these changes were statistically significant. The $\mathrm{CV}$ was in the order $\mathrm{B}<\mathrm{C}<\mathrm{A}$ at all visits with significantly lower $\mathrm{CV}$ in $\mathrm{B}$ versus $\mathrm{A}$ at

Table 2 Correlation between nuclear grade and per-operative parameters

\begin{tabular}{|c|c|c|c|c|}
\hline & & & $\mathrm{NC}$ & $\mathrm{NO}$ \\
\hline \multirow[t]{12}{*}{$\begin{array}{l}\text { Spearman's } \\
\text { rho }\end{array}$} & Age (years) & $\begin{array}{l}\text { Correlation } \\
\text { Coefficient }\end{array}$ & $.379^{a}$ & $.366^{\mathrm{a}}$ \\
\hline & & Sig. (2-tailed) & .00001 & .00003 \\
\hline & & $\mathrm{N}$ & 126 & 126 \\
\hline & $\begin{array}{l}\text { CDE } \\
\text { (\%-seconds) }\end{array}$ & $\begin{array}{l}\text { Correlation } \\
\text { Coefficient }\end{array}$ & $.660^{\mathrm{a}}$ & $.643^{\mathrm{a}}$ \\
\hline & & Sig. (2-tailed) & $<.0001$ & $<.0001$ \\
\hline & & N & 125 & 125 \\
\hline & TAT (seconds) & $\begin{array}{l}\text { Correlation } \\
\text { Coefficient }\end{array}$ & $.619^{\mathrm{a}}$ & $.610^{\mathrm{a}}$ \\
\hline & & Sig. (2-tailed) & $<.0001$ & $<.0001$ \\
\hline & & $\mathrm{N}$ & 126 & 126 \\
\hline & EFU (ml) & $\begin{array}{l}\text { Correlation } \\
\text { Coefficient }\end{array}$ & $.613^{\mathrm{a}}$ & $.596^{\mathrm{a}}$ \\
\hline & & Sig. (2-tailed) & $<.0001$ & $<.0001$ \\
\hline & & $\mathrm{N}$ & 126 & 126 \\
\hline
\end{tabular}

$C D E=$ cumulative dissipated energy, $T A T=$ total aspiration time, $E F U=$ estimated fluid usage

${ }^{\text {a }}$ Correlation is significant at the 0.01 level (2-tailed)
3 months and 6 months postop, while the hexagonal endothelial cell count was in the order $\mathrm{A}>\mathrm{B}>\mathrm{C}$ at 1 week and 1 month and $\mathrm{A}>\mathrm{C}>\mathrm{B}$ at 3 and 6 months with significantly higher counts in A vs. B only at the one week postop visit (Table 4).

As absolute values may not be representative especially when baseline values of each cornea change its susceptibility to endothelial damage, it is more relevant to study the change in parameters over time and compare between the three intervention groups. An analysis was done to compare percentage changes from baseline in endothelial parameters between the three groups at each follow up visit. Percentage changes were calculated as difference between final \& baseline values divided by baseline values and multiplied by 100 .

Initially, significantly lower percentage losses in ECD were seen in group $\mathrm{A}$ in comparison to group $\mathrm{B}$ as well as group $C$ at 1 week, and in group $A$ versus group $C$ at 1 month. However, there was no significant difference in percentage losses in cell density among the three groups at the 3 months follow up. But by 6 months, losses were significantly lower only in group $\mathrm{C}$ as compared to group B. Significantly higher increase in CCT was seen in group $\mathrm{B}$ in comparison to both the other groups at 1 week and in comparison to group A at 1 month. However, there was no significant difference in percentage change in corneal thickness among the three groups at 3 months follow up. In all groups, CCT decreased over time but the decrease was significantly lower in group B as compared to group A at 6 months.

Significant increase in $\mathrm{CV}$ was seen in group $\mathrm{C}$ in comparison to groups $\mathrm{A}$ and $\mathrm{B}$ and in group $\mathrm{B}$ in comparison to group $\mathrm{A}$ at 1 week. The increase in $\mathrm{CV}$ remained significant higher in group $C$ versus group $A$ and $B$ at all postoperative visits.

There was no significant difference in change in hexagonal endothelial cell count between three groups at 1 week follow up; however, the change in hexagonal endothelial cell count was significantly lower in group $\mathrm{C}$ in comparison to groups $\mathrm{A}$ and $\mathrm{B}$ at 1, 3 and 6 months follow up (Table 5).

As age and nuclear grade can affect endothelial cell loss, we asked if there were any endothelial salvaging effects with respect to the phacoemulsification system used. An ANCOVA test was performed to compare changes in the endothelium after adjusting for these confounders. Interestingly, even after adjusting for these variables, the results remained significant (Table 6).

\section{Discussion}

A lower $\mathrm{CDE}$ is one parameter that all surgeons vie to achieve due to the obvious benefits of reduced energy delivery, which correlates with less damage to the endothelium and lower complication rates [7]. Torsional 
Table 3 Comparison of per-operative parameters between three groups

\begin{tabular}{|c|c|c|c|c|c|c|c|c|}
\hline & Group A & Group B & Group C & $p$ value & $A$ vs $B$ & A vs $C$ & B vs C & \\
\hline \multicolumn{9}{|l|}{ CDE (\%-seconds) } \\
\hline Sample size & 42 & 42 & 42 & & & & & \\
\hline Mean \pm SD & $13.14 \pm 7.65$ & $11.33 \pm 5.14$ & $7.70 \pm 4.59$ & 0.001 & 0.35 & 0.001 & 0.001 & Kruskal Wallis \\
\hline Median & 12.38 & 11.04 & 6.84 & & & & & \\
\hline Min-Max & $1.48-28.20$ & $2.13-20.86$ & $1.15-16.79$ & & & & & \\
\hline Inter quartile Range & $6.40-20.80$ & $7.02-16.21$ & 3.69-11.94 & & & & & \\
\hline \multicolumn{9}{|l|}{$\mathrm{EFU}(\mathrm{ml})$} \\
\hline Sample size & 42 & 42 & 42 & & & & & \\
\hline Mean \pm Stdev & $58.19 \pm 19.10$ & $46.86 \pm 12.38$ & $34.81 \pm 10.47$ & $<.0001$ & 0.015 & $<.0001$ & $<.0001$ & Kruskal Wallis \\
\hline Median & 55.0 & 48.5 & 36.5 & & & & & \\
\hline Min-Max & 30-92 & $19-74$ & $16-56$ & & & & & \\
\hline Inter quartile Range & $40-78$ & $39-56$ & $26-41$ & & & & & \\
\hline \multicolumn{9}{|l|}{ TAT (seconds) } \\
\hline Sample size & 42 & 42 & 42 & & & & & \\
\hline Mean \pm Stdev & $172.71 \pm 94.92$ & $131.00 \pm 45.20$ & $113.36 \pm 56.50$ & 0.001 & 0.299 & 0.0004 & 0.002 & Kruskal Wallis \\
\hline Median & 132.5 & 125.0 & 95.0 & & & & & \\
\hline Min-Max & $61-437$ & $61-251$ & $63-364$ & & & & & \\
\hline Inter quartile Range & $95-245$ & $96-168$ & $79-122$ & & & & & \\
\hline
\end{tabular}

$C D E=$ cumulative dissipated energy, $E F U=$ estimated fluid usage, $T A T=$ total aspiration time

phacoemulsification reduces energy delivery in the eye in comparison to longitudinal phacoemulsification [8]. In addition, better fluidic management increases the efficiency of phacoemulsification to result in lower energy delivery and at the same time, a stable anterior chamber correlates with lower endothelial cell loss [9].

While previous machines have traditionally used gravity fed infusion systems, some drawbacks were apparent [10]. An attempt was made to use more stable modalities like an air pump or pressurised irrigation bottle with gas with some benefits. However, as the gas infusion pressure does not necessarily vary in response to the changing aspiration flow rate, the effect is the same as raising the bottle height $[4,11]$. More recent machines maintain IOP by using a compliant irrigation bag, which is squeezed in response to the aspiration flow rate and estimated incision leakage. Centurion uses an Active Fluidics Technology as compared to a gravity fed infusion system in the Infiniti [4].

Instead of a bag or bottle suspended above the machine to use gravity as just described, there is a compartment into which a bag of balanced salt solution (BSS) (Alcon Laboratories, Inc.) is placed between two paddles. The bag is made of a polymer which, under the pressures to which it is subjected, is almost stretch-free. This means that very small and precise movements of the electronically controlled paddles against the bag are designed to lead to exquisite control of the fluid entering the eye. This control is part of the technology called ACTIVE FLUIDICS, which allows the surgeon to choose a target IOP. To assist in the way the paddles move, the outflow and inflow from the CENTURION Vision System are monitored by pressure sensors on the Fluidics Management System (FMS). To speed the responsiveness and thus rise time, there are two rotary valves. The pump itself now has seven rollers, compared with four on the INFINITI Vision System (Alcon Laboratories, Inc.). These seven rollers act on the entire $360^{\circ}$ of the tubing in which they are in contact, compared with only $180^{\circ}$ on the INFINITI Vision System. This again is designed to lead to improved response times. The aspiration tubing has a reduced inner diameter of $0.048 \mathrm{~mm}$ in comparison to $0.057 \mathrm{~mm}$ of the Intrepid plus FMS being used in the INFINITI and is also very difficult to compress. This is designed to have two effects: firstly, to increase resistance to flow; and second, to prevent any tubing from collapsing, which can reduce post-occlusion surge and thus increase anterior chamber stability. This system therefore provides an active control of infusion pressure to maintain a more stable target IOP level in spite of variations in aspiration flow rates [12, 13].

An experimental study with the Infiniti versus Centurion Gravity versus Centurion Active has shown better IOP maintenance and thus surge protection with Centurion Active as compared to other gravity fed systems at increasing aspiration flow rates. However, in view of an artificial anterior chamber used in the study, it was recommended that comparative studies are performed using the tissue globe environment $[4,5,12]$. 
Table 4 Comparison of postoperative endothelial parameters between three groups

\begin{tabular}{|c|c|c|c|c|c|c|c|c|}
\hline & Group A $(n=42)$ & Group B $(n=42)$ & Group C $(n=42)$ & $p$ value & A vs. B & A vs. C & B vs. C & \\
\hline \multicolumn{4}{|c|}{ ECD Pre-op (cell/mm²) } & 0.876 & 0.804 & 0.793 & 0.605 & Anova \\
\hline Mean \pm SD & $2516.00 \pm 211.54$ & $2527.17 \pm 199.39$ & $2503.86 \pm 212.23$ & & & & & \\
\hline \multicolumn{4}{|l|}{ ECD 1 week } & 0.712 & 0.959 & 0.499 & 0.463 & Anova \\
\hline Mean \pm SD & $2321.52 \pm 201.18$ & $2323.74 \pm 196.11$ & $2291.21 \pm 207.79$ & & & & & \\
\hline \multicolumn{4}{|l|}{ ECD 1 month } & 0.750 & 0.958 & 0.538 & 0.504 & Anova \\
\hline Mean \pm SD & $2227.45 \pm 192.59$ & $2229.69 \pm 191.33$ & $2200.00 \pm 213.59$ & & & & & \\
\hline \multicolumn{4}{|l|}{ ECD 3 months } & 0.802 & 0.909 & 0.618 & 0.546 & Anova \\
\hline Mean \pm SD & $2122.69 \pm 192.24$ & $2127.48 \pm 191.61$ & $2099.95 \pm 223.45$ & & & & & \\
\hline \multicolumn{4}{|l|}{ ECD 6 months } & 0.515 & 0.558 & 0.378 & 0.308 & Kruskal Wallis \\
\hline Mean \pm SD & $2007.24 \pm 196.61$ & $2012.07 \pm 190.15$ & $2005.81 \pm 216.72$ & & & & & \\
\hline \multicolumn{4}{|l|}{ сCT Pre-op ( $\mu \mathrm{m})$} & 0.777 & 0.514 & 0.951 & 0.561 & Anova \\
\hline Mean \pm SD & $531.21 \pm 25.45$ & $526.88 \pm 34.47$ & $531.67 \pm 40.52$ & & & & & \\
\hline \multicolumn{4}{|l|}{ CCT 1 week } & 0.996 & 0.988 & 0.946 & 0.943 & Anova \\
\hline Mean \pm SD & $549.81 \pm 23.32$ & $549.71 \pm 33.81$ & $550.29 \pm 39.25$ & & & & & \\
\hline \multicolumn{4}{|l|}{ CCT 1 month } & 0.949 & 0.794 & 0.943 & 0.781 & Anova \\
\hline Mean \pm SD & $538.79 \pm 24.52$ & $537.10 \pm 33.77$ & $539.29 \pm 38.11$ & & & & & \\
\hline \multicolumn{4}{|l|}{ CCT 3 months } & 0.578 & 0.792 & 0.479 & 0.301 & Kruskal Wallis \\
\hline Mean \pm SD & $528.10 \pm 24.79$ & $523.83 \pm 31.7$ & $528.33 \pm 39.39$ & & & & & \\
\hline \multicolumn{4}{|l|}{ ССТ 6 month } & 0.632 & 0.847 & 0.39 & 0.439 & Kruskal Wallis \\
\hline Mean \pm SD & $525.57 \pm 24.39$ & $524.43 \pm 33.84$ & $526.81 \pm 39.55$ & & & & & \\
\hline \multicolumn{4}{|l|}{ CV Pre-op (\%) } & 0.022 & 0.017 & 0.017 & 0.832 & Kruskal Wallis \\
\hline Mean \pm SD & $39.86 \pm 3.85$ & $38.00 \pm 3.78$ & $38.07 \pm 3.80$ & & & & & \\
\hline \multicolumn{4}{|l|}{ CV 1 week } & 0.056 & 0.024 & 0.064 & 0.736 & Kruskal Wallis \\
\hline Mean \pm SD & $44.14 \pm 4.22$ & $42.14 \pm 3.82$ & $42.60 \pm 4.16$ & & & & & \\
\hline \multicolumn{4}{|l|}{ CV 1 month } & 0.082 & 0.038 & 0.55 & 0.105 & Anova \\
\hline Mean \pm SD & $39.98 \pm 3.87$ & $38.24 \pm 3.67$ & $39.50 \pm 3.38$ & & & & & \\
\hline \multicolumn{4}{|l|}{ CV 3 months } & 0.043 & 0.02 & 0.55 & 0.056 & Kruskal Wallis \\
\hline Mean \pm SD & $39.21 \pm 3.58$ & $37.43 \pm 3.61$ & $38.90 \pm 3.59$ & & & & & \\
\hline \multicolumn{4}{|l|}{ CV 6 months } & & & & & Kruskal Wallis \\
\hline Mean \pm SD & $43.17 \pm 3.30$ & $40.64 \pm 3.57$ & $42.90 \pm 3.47$ & 0.001 & 0.001 & 0.52 & 0.004 & \\
\hline \multicolumn{4}{|l|}{ 6A Pre-op (\%) } & 0.004 & 0.256 & 0.001 & 0.028 & Kruskal Wallis \\
\hline Mean \pm SD & $49.88 \pm 6.14$ & $48.67 \pm 5.80$ & $45.45 \pm 5.60$ & & & & & \\
\hline \multicolumn{4}{|l|}{ 6A 1 week } & 0.051 & 0.569 & 0.02 & 0.073 & Kruskal Wallis \\
\hline Mean \pm SD & $32.90 \pm 5.56$ & $31.90 \pm 3.76$ & $30.17 \pm 4.50$ & & & & & \\
\hline \multicolumn{4}{|l|}{ 6A 1 month } & 0.642 & 0.943 & 0.388 & 0.448 & Kruskal Wallis \\
\hline Mean \pm SD & $38.36 \pm 5.64$ & $38.14 \pm 4.18$ & $37.36 \pm 4.29$ & & & & & \\
\hline \multicolumn{4}{|l|}{6 A 3 months } & 0.997 & 0.964 & 0.928 & 0.986 & Kruskal Wallis \\
\hline Mean \pm SD & $43.93 \pm 4.97$ & $43.69 \pm 3.82$ & $43.76 \pm 3.97$ & & & & & \\
\hline \multicolumn{4}{|l|}{$6 \mathrm{~A} 6$ months } & 0.995 & 0.964 & 0.91 & 0.975 & Kruskal Wallis \\
\hline Mean \pm SD & $45.93 \pm 4.97$ & $45.69 \pm 3.82$ & $45.74 \pm 3.96$ & & & & & \\
\hline
\end{tabular}

$E C D=$ endothelial cell density, $C C T=$ central corneal thickness, $C V=$ coefficient of variance, $6 A=$ percentage of hexagonal endothelial cells

Previous studies have shown lowered CDE in the Centurion as compared to the Infiniti [4, 14-16]. According to the manufacturer, two unique improvements in the Centurion are: active fluid dynamic management system and use of an Intrepid balanced tip [17]. 
Table 5 Percentage changes of endothelial cell density, central corneal thickness, coefficient of variance and hexagonal endothelial cells between three groups

\begin{tabular}{|c|c|c|c|c|c|c|c|c|}
\hline Percentage changes & $A(n=42)$ & $B(n=42)$ & $C(n=42)$ & $p$ value & A vs. B & A vs. C & B vs. C & \\
\hline ECD 1 week & & & & 0.016 & 0.037 & 0.007 & 0.444 & Kruskal Wallis \\
\hline Mean \pm SD & $7.75 \pm 0.84$ & $8.08 \pm 1.03$ & $8.54 \pm 1.47$ & & & & & \\
\hline ECD 1 month & & & & 0.071 & 0.18 & 0.031 & 0.264 & Anova \\
\hline Mean \pm SD & $11.48 \pm 0.85$ & $11.81 \pm 1.32$ & $12.22 \pm 2.00$ & & & & & \\
\hline ECD 3 months & & & & 0.634 & 0.352 & 0.491 & 0.876 & Kruskal Wallis \\
\hline Mean \pm SD & $15.66 \pm 1.53$ & $15.88 \pm 1.43$ & $16.29 \pm 3.24$ & & & & & \\
\hline ECD 6 months & & & & 0.061 & 0.671 & 0.069 & 0.027 & Kruskal Wallis \\
\hline Mean \pm SD & $20.31 \pm 1.29$ & $20.47 \pm 1.53$ & $20.06 \pm 3.06$ & & & & & \\
\hline CCT 1 week & & & & 0.006 & 0.001 & 0.379 & 0.038 & Kruskal Wallis \\
\hline Mean \pm SD & $-3.62 \pm 1.36$ & $-4.36 \pm 0.84$ & $-3.57 \pm 2.27$ & & & & & \\
\hline CCT 1 month & & & & 0.089 & 0.016 & 0.737 & 0.096 & Anova \\
\hline Mean \pm SD & $-1.38 \pm 1.23$ & $-1.96 \pm 0.88$ & $-1.49 \pm 1.58$ & & & & & \\
\hline CCT 3 months & & & & 0.205 & 0.114 & 0.985 & 0.135 & Kruskal Wallis \\
\hline Mean \pm SD & $0.63 \pm 1.33$ & $0.51 \pm 2.83$ & $0.61 \pm 1.41$ & & & & & \\
\hline CCT 6 months & & & & 0.110 & 0.033 & 0.648 & 0.17 & Kruskal Wallis \\
\hline Mean \pm SD & $1.05 \pm 1.32$ & $0.46 \pm 0.86$ & $0.9 \pm 1.42$ & & & & & \\
\hline CV 1 week & & & & $<.0001$ & 0.041 & 0.0001 & 0.003 & Kruskal Wallis \\
\hline Mean \pm SD & $-10.81 \pm 3.11$ & $-11.00 \pm 1.45$ & $-11.99 \pm 4.46$ & & & & & \\
\hline CV 1 month & & & & $<.0001$ & 0.166 & $<.0001$ & $<.0001$ & Kruskal Wallis \\
\hline Mean \pm SD & $-0.34 \pm 2.77$ & $-0.69 \pm 2.84$ & $-3.97 \pm 4.63$ & & & & & \\
\hline CV 3 months & & & & $<.0001$ & 0.762 & $<.0001$ & $<.0001$ & Kruskal Wallis \\
\hline Mean \pm SD & $1.54 \pm 2.35$ & $1.45 \pm 2.45$ & $-2.34 \pm 4.54$ & & & & & \\
\hline CV 6 months & & & & $<.0001$ & 0.055 & $<.0001$ & $<.0001$ & Anova \\
\hline Mean \pm SD & $-8.55 \pm 3.71$ & $-7.11 \pm 3.07$ & $-12.98 \pm 5.16$ & & & & & \\
\hline 6A 1 week & & & & 0.803 & 0.926 & 0.63 & 0.534 & Anova \\
\hline Mean \pm SD & $34.19 \pm 5.59$ & $34.29 \pm 4.28$ & $33.57 \pm 6.12$ & & & & & \\
\hline 6A 1 month & & & & 0.002 & 0.308 & 0.001 & 0.005 & Kruskal Wallis \\
\hline Mean \pm SD & $23.04 \pm 6.46$ & $21.32 \pm 5.67$ & $17.32 \pm 8.67$ & & & & & \\
\hline 6 A 3 months & & & & $<.0001$ & 0.534 & $<.0001$ & 0.0004 & Kruskal Wallis \\
\hline Mean \pm SD & $11.43 \pm 7.85$ & $9.65 \pm 7.11$ & $2.96 \pm 9.54$ & & & & & \\
\hline $6 \mathrm{~A} 6$ months & & & & $<.0001$ & 0.274 & $<.0001$ & 0.0004 & Anova \\
\hline Mean \pm SD & $7.36 \pm 8.15$ & $5.48 \pm 7.49$ & $-1.62 \pm 9.95$ & & & & & \\
\hline
\end{tabular}

$E C D=$ endothelial cell density, $C C T=$ central corneal thickness, $C V=$ coefficient of variance, $6 A=$ percentage of hexagonal endothelial cells

Apart from the surgeon's skill and technique, use of torsional phaco instead of longitudinal can have further lowered $\mathrm{CDE}$ and fluid usage if the cutting efficiency of the tip is maximized. If we try to visualize the tip movement in the lens during torsional phacoemulsification, two things gain importance. First, an increasing bevel exposes a greater cross-sectional area to lens matter, increasing its cutting efficiency. Secondly, the bend in the shaft of the tip increases the area it traverses on each stroke so the 22-degree bent 30-degree Kelman mini-flared tip cuts longer than the 12-degree bent 30-degree mini-flared Kelman tip [18, 19].
Design of phacotips for torsional phacoemulsification has evolved over time specially to get the best out of torsional mode of phacoemulsification. The Kelman style angled tip was followed by mini flared ABS Kelman tip and then the 45-degree tip, which has significantly better cutting action and repositioning of the lens material than the 30-degree bevelled tip [18, 20-22]. Lower CDE and less CCT changes have been observed with the 45-degree aperture angled tip than with the 30-degree aperture angled tip [23]. 
Table 6 Percentage changes of endothelial cell density, centra corneal thickness, coefficient of variance and hexagonal endothelial cells between three groups after adjusting for age, $\mathrm{NC}$, and $\mathrm{NO}$

\begin{tabular}{|c|c|c|c|}
\hline \multirow[t]{2}{*}{ Percentage Changes } & \multicolumn{3}{|c|}{ After adjusting for age, NC, NO } \\
\hline & A vs. B & A vs. C & B vs. C \\
\hline ECD 1 week & 0.109 & 0.003 & 0.154 \\
\hline \multicolumn{4}{|l|}{ Mean \pm SD } \\
\hline ECD 1 month & 0.155 & 0.017 & 0.453 \\
\hline \multicolumn{4}{|l|}{ Mean \pm SD } \\
\hline ECD 3 months & 0.399 & 0.249 & 0.559 \\
\hline \multicolumn{4}{|l|}{ Mean \pm SD } \\
\hline ECD 6 months & 0.402 & 0.738 & 0.315 \\
\hline \multicolumn{4}{|l|}{ Mean \pm SD } \\
\hline CCT 1 week & 0.002 & 0.705 & 0.006 \\
\hline \multicolumn{4}{|l|}{ Mean \pm SD } \\
\hline CCT 1 month & 0.011 & 0.859 & 0.015 \\
\hline \multicolumn{4}{|l|}{ Mean \pm SD } \\
\hline CCT 3 months & 0.821 & 0.979 & 0.65 \\
\hline \multicolumn{4}{|l|}{ Mean \pm SD } \\
\hline CCT 6 months & 0.021 & 0.652 & 0.033 \\
\hline \multicolumn{4}{|l|}{ Mean \pm SD } \\
\hline CV 1 week & 0.646 & 0.254 & 0.161 \\
\hline \multicolumn{4}{|l|}{ Mean \pm SD } \\
\hline CV 1 month & 0.556 & 0.0001 & 0.0003 \\
\hline \multicolumn{4}{|l|}{ Mean \pm SD } \\
\hline CV 3 months & 0.874 & $<.0001$ & $<.0001$ \\
\hline \multicolumn{4}{|l|}{ Mean \pm SD } \\
\hline CV 6 months & 0.069 & $<.0001$ & $<.0001$ \\
\hline \multicolumn{4}{|l|}{ Mean \pm SD } \\
\hline 6A 1 week & 0.998 & 0.478 & 0.577 \\
\hline \multicolumn{4}{|l|}{ Mean \pm SD } \\
\hline 6A 1 month & 0.214 & 0.001 & 0.031 \\
\hline \multicolumn{4}{|l|}{ Mean \pm SD } \\
\hline 6 A 3 months & 0.291 & 0.0001 & 0.001 \\
\hline \multicolumn{4}{|l|}{ Mean \pm SD } \\
\hline $6 \mathrm{~A} 6$ months & 0.291 & $<.0001$ & 0.001 \\
\hline Mean \pm SD & & & \\
\hline
\end{tabular}

$E C D=$ endothelial cell density, $C C T=$ central corneal thickness, $C V=$ coefficient of variance, $6 A=$ percentage of hexagonal endothelial cells

However, the Kelman tips have significant motion of the shaft as well, which can lead to heat production and undesired corneal changes at the incision. The Intrepid balanced tip has enhanced sideways displacement at the tip end and greatly reduced tip action along the shaft. It has a stroke length of $192 \mu \mathrm{m}$ at $100 \%$ OZIL as compared to $130 \mu \mathrm{m}$ at $100 \%$ OZIL with $45^{\circ}$ Kelman miniflare $\mathrm{ABS}$. Lower $\mathrm{CDE}$ and no wound changes are attributed to the increased emulsification and cavitation at the sides of the INTREPID balanced tip but no significant phacotip shaft motion was seen with the balanced tip [8, 24]. An independent comparative study of the designs of the $45^{\circ}$ Kelman and $45^{\circ}$ balanced phacotip showed less total US time, torsional time, CDE and BSS use as well as similar changes in the ECD with a balanced tip [25].

Similar results were reported using these two tip designs in the CENTURION in patients belonging to the same ethnic group as us [26]. In our study, we too found that the use of the Intrepid balanced tip in combination with Active Fluidics was associated with significant reduction in CDE, EFU as well as TAT in comparison to the other groups using a $45^{\circ}$ Kelman tip on either a gravity fed or IOP fed fluidic system.

The reduced energy delivery and stable IOP should also translate to healthier corneas. There exists a relation between ultrasound power and corneal endothelium with increased energy usage being associated with endothelial cell loss. CDE is only one way of expressing ultrasonic energy usage. CDE is an estimation of the energy at the incision site experienced during the removal of cataractous lens and is measured in \%-secs. The incision is defined as $5.6 \mathrm{~mm}$ back from the cutting edge of the tip. A lower CDE indicates that less energy was present at the incision site [27]. This should ideally reflect higher incision burn with increased CDE [28].

But what we are interested in is not just the effect on the endothelium at the incision site but the overall health of the entire and more usefully central endothelium. Comparing CDE with tip designs varying in length may not exactly be representative as ideal comparisons and we might end up comparing apples to oranges instead of apples to apples [6]. Also, reduced CDE even though good at incision may not always result in reduced energy delivery in the anterior chamber if greater tip excursion and cavitation are being achieved [9].

This justifies choosing technical modifications that have equivalent or safer endothelial results if other benefits of reduced ultrasound time, EFU and in addition, CDE are present. A previous study comparing 2 tip designs had revealed that balanced tip use is associated with less total ultrasound time, torsional time, CDE and BSS use with similar changes in ECD as with the Kelman tip.

In our study, there was a direct correlation between $\mathrm{CDE}$ and the nuclear grade indicating that higher grades of cataract required more phaco energy. Similar results were shown in a study by Liu et al. where increase in CDE was seen with higher grades of nuclear density [29]. We also saw that higher grades of cataract correlated significantly with increases in CDE, EFU and TAT. Thus, the changes in endothelial status were compared across three groups after adjusting for any possible effect 
of age and nuclear grade and found that at 6 months, changes in ECD were comparable among 3 groups with group B showing greater increase in CCT. Although group $\mathrm{C}$ had significantly higher increase in $\mathrm{CV}$ than the other two groups, it had better preservation of hexagonal endothelial cell counts. This suggested comparable endothelial safety between three groups with added advantage of lowered CDE, EFU and TAT in the Centurion with an Intrepid balanced tip.

Even if we were to correlate CDE with incision temperature only, we cannot ignore the lowered EFU as well as TAT with the use of Centurion in the setting of comparably safe endothelium even up to six months follow up. Thus, we recommend using the Centurion system with the Intrepid balanced tip to obtain its maximum benefit in terms of reduction in $\mathrm{CDE}$, EFU and TAT.

\section{Conclusions}

Use of an IOP based phacoemulsification system in association with the use of an Intrepid balanced tip provides comparable endothelial results as well as reduces the CDE, EFU and TAT versus a gravity fed system with mini flare tip or IOP based system with mini flare tip.

\section{Abbreviations \\ 6A: Hexagonal endothelial cells; BSS: Balanced salt solution; CCT: Central corneal thickness; CDE: Cumulative dissipated energy; CV: Coefficient of variance; EFU: Estimated fluid usage; IOP: Intraocular pressure; LOCS III: Lens opacities classification system ш; NC: Nuclear colour; NO: Nuclear opalescenceECDEndothelial cell density; OPD: Out patient department; SD: Standard deviation; TAT: Total aspiration time}

\section{Acknowledgements}

Not applicable

\section{Funding}

Not applicable

\section{Availability of data and materials}

Not applicable

\section{Authors' contributions}

Conception,design and drafting the article by Dr. PKM and Dr. TD. Drafting of article by Dr. AKP. Acquisition and Analysis of data by Dr. ES. All authors read and approved the final manuscript.

\section{Ethics approval and consent to participate}

The study was approved by the Institutional Ethics Committee and consent of participants were also taken.

\section{Consent for publication}

Not applicable

\section{Competing interests}

The authors declare that they have no competing interests.

Received: 27 April 2017 Accepted: 2 September 2017

Published online: 17 September 2017

\section{References}

1. Olson LE, Marshall J, Rice NS, Andrews R. Effects of ultrasound on the corneal endothelium: I. The acute lesion. Br J Ophthalmol. 1978;62:134-44.
2. Helvacıoğlu F, Şencan S, Tunç Z, Yeter C. Torsional phacoemulsification and tip selection. Turk J Ophthalmol. 2014;44:392-5.

3. Wunder H. Tip design adds punch to your Phaco technique. Rev Ophthalmol. 2003:9:62

4. Chen M, Anderson E, Hill G, Chen JJ, Patrianakos T. Comparison of cumulative dissipated energy between the Infiniti and Centurion phacoemulsification systems. Clin Ophthalmol. 2015;9:1367-72.

5. Nicoli CM, Dimalanta R, Miller KM. Experimental anterior chamber maintenance in active versus passive phacoemulsification fluidics systems. J Cataract Refract Surg. 2016:42:157-62.

6. Mamalis N. Which phacoemulsification modalities are the best? Comparing apples to apples. J Cataract Refract Surg. 2015;41:255-6.

7. Mahdy MA, Eid MZ, Mohammed MA, Hafez A, Bhatia J. Relationship between endothelial cell loss and microcoaxial phacoemulsification parameters in noncomplicated cataract surgery. Clin Ophthalmol. 2012;6:503-10.

8. Miyoshi T, Yoshida $\mathrm{H}$. Emulsification action of longitudinal and torsional ultrasound tips and the effect on treatment of the nucleus during phacoemulsification. J Cataract Refract Surg. 2010;36:1201-6.

9. Reuschel A, Bogatsch H, Barth T, Wiedemann R. Comparison of endothelial changes and power settings between torsional and longitudinal phacoemulsification. J Cataract Refract Surg. 2010;36:1855-61.

10. White FM. Fluid mechanics. New York: McGraw-Hill; 1986.

11. Chaudhry P, Prakash G, Jacob S, Narasimhan S, Agarwal S, Agarwal A. Safety and efficacy of gas-forced infusion (air pump) in coaxial phacoemulsification. J Cataract Refract Surg. 2010;36:2139-45.

12. Devgun U. Optimizing phaco fluidics creates more stable environment for cataract surgery. U.S.: Ocular Surgery News; 2014. https://www.healio.com/ ophthalmology/cataract-surgery/news/print/ocular-surgery-news/ \%7Bfb82b5ca-23b0-49ad-b87e-3d9f60f625f7\%7D/. Accessed 5 July 2017.

13. Allen D. Enhanced speed and control with the CENTURION vision system. http:// crstoday.com/articles/2014-novdec/1114_insert4-pdf/. Accessed 5 July 2017.

14. Solomon KD, Lorente R, Cionni RJ, Fanney D. Prospective randomized clinical study using a new phaco system with intraocular system target pressure control. In: The ASCRS meeting. Boston: 2014.

15. Woodard L. The centurion vision system. Cataract and Refractive Surgery Today. 2016:43-5

16. Tognetto D. CENTURION vision system: my experience. Cataract and Refractive Surgery Today. 2015:1-2.

17. Mackool RJ. Phaco without gravity based fluidics. Cataract and Refractive Surgery Today. 2014:4-5.

18. Kim EK, Jo K, Joo CK. Comparison of tips in coaxial microincision cataract surgery with the bevel- down technique. J Cataract Refract Surg. 2011;37:2028-33.

19. Helvacioglu F, Yeter C, Tunc Z, Sencan S. Outcomes of torsional microcoaxial phacoemulsification performed by 12-degree and 22-degree bent tips. J Cataract Refract Surg. 2013;39:1219-25.

20. Fishkind WJ, Neuhann TF, Steinert RF. The phaco machine: the physical principles guiding its operation. In: Steinert RF, editor. Cataract surgery: technique, complications, and management. Philadelphia: Saunders; 2004. p. 69-73.

21. Zanini M, Savini G, Buratto L. Physical principles of phacoemulsification. In: Buratto L, Werner L, Zanini M, Apple D, editors. Phacoemulsification: principles and techniques. 2nd ed. Thorofare, NJ: Slack Inc; 2003. p. 41-3.

22. Hida WT, Tzelikis PF, Nakano CT, Motta AF, Alves MR. Mini-flared Kelman tip, reverse tip, and sidewinder tip with torsional phaco: a prospective randomized comparative study. Arq Bras Oftalmol. 2015;78:19-22.

23. Helvacioglu F, Sencan S, Yeter C, Tunc Z, Uyar OM. Outcomes of torsional microcoaxial phacoemulsification using tips with 30-degree and 45-degree aperture angles. J Cataract Refract Surg. 2014;40:362-8.

24. Tjia KF. Novel balanced phaco tip for microcoaxial torsional phaco. In: ASCRS-ASOA Symposium and Congress on Cataract, IOL and Refractive Surgery. Boston: 2014

25. Demircan S, Ataş M, Göktaş E, Başkan B. Comparison of 45-degree Kelman and 45-degree balanced phaco tip designs in torsional microcoaxial phacoemulsification. Int J Ophthalmol. 2015;8(6):1168-72.

26. Khokhar S, Aron N, Sen S, Pillay G, Agarwal E. Effect of balanced phacoemulsification tip on the outcomes of torsional phacoemulsification using an active-fluidics system. J Cataract Refract Surg. 2017;43(1):22-8.

27. Intra-Operative Metrics with Centurion and Infiniti Vision Systems. https://clinicaltrials.gov/ct2/show/NCT01848288. Accessed 6 Sept 2017. 
28. Sorensen T, Chan CC, Bradley M, Braga-Mele R, Olson RJ. Ultrasoundinduced corneal incision contracture survey in the United States and Canada. J Cataract Refract Surg. 2012;38:227-33.

29. Liu Y, Zeng M, Liu X, Luo L, Yuan Z, Xia Y, et al. Torsional mode versus conventional ultrasound mode phacoemulsification: randomized comparative clinical study. J Cataract Refract Surg. 2007;33:287-92.

Submit your next manuscript to BioMed Central and we will help you at every step:

- We accept pre-submission inquiries

- Our selector tool helps you to find the most relevant journal

- We provide round the clock customer support

- Convenient online submission

- Thorough peer review

- Inclusion in PubMed and all major indexing services

- Maximum visibility for your research

Submit your manuscript at www.biomedcentral.com/submit 